\title{
Organ donations should not be restricted to relatives
}

\author{
Martyn Evans University College, Swansea
}

\section{Author's abstract}

Should we remove whole organs from living donors only in the case where they are genetically related to the intended recipients of such organs? The practice in a majority of European nations is to apply such a restriction. Yet this restriction obviously limits the availability of already scarce donor organs, and curtails the opportunities for altruistic action on the part of those who, in any given case, are not genetically related to the recipient.

The author argues that we have a duty to maximise procurement of organs, and that we should respect the 'genetic relative' restriction only in response to compelling moral reasons. The author considers the principal objections to non-related donation and shows them to be misdirected. He concludes that non-related donation should be welcomed where clinically appropriate and truly voluntary.

\section{The problem}

Should we remove whole organs from living donors only when those donors are genetically related to the intended recipient? The clinical considerations alone might indicate that, in pursuit of a suitable 'match' for a potential recipient, we should ordinarily restrict ourselves to just such donors. But such donors are not always available. They may simply not exist - the intended recipient may have no close surviving relatives. Or they may be too old, too young or too frail to undergo the procurement surgery. They may not be able to afford to lose, for instance, a kidney (to take the principal example of living donation). Or there may be other clinical reasons why their kidneys would be unsuitable. And perhaps, most obviously, they simply may not be willing to make the sacrifice involved. When any of these circumstances obtains, why should we not simply look elsewhere for a sufficiently close 'match' from a non-related donor who is both able and willing to make a gift of the required organ?

This question has been raised, in connection with producing legislation on live organ donation, by the

\section{Key words}

Live organ donation; genetic relative; duties; consequences; altruism; vulnerability; exploitation; consistency. relevant authorities in most European countries, and for the purposes of this article I will confine myself to the substance of their discussion. Their various answers may be found in two most useful documents published by the Council of Europe, both emanating from a recent Conference of European Health Ministers on the issue of organ transplantation (1). The first document summarises the rather divided views which emerge from a joint questionnaire submitted to, and completed by, the respective governments:

'In the living donor, the removal of double or regenerative organs is accepted by most member states as not contrary to ethics on the condition that free and enlightened consent has been obtained from the future donor and that the donor is genetically related to the recipient [my emphasis].

'Where the future donor is only legally related (spouse) the positions are less clear as one can very easily imagine that the reasons which lead one spouse to donate a kidney to improve the other's living conditions have a real and profound emotional basis. On the other hand, opinions concerning organ removal from unrelated living persons are very divided, although a majority is emerging against this practice. These differences of opinion between countries are very often evidence of inequalities of access to periodic haemodialysis. There is no doubt that people will be more inclined to accept the removal of kidneys from unrelated living donors when this practice makes it possible to save a patient's life than when it merely makes it possible to improve the living conditions of a patient requiring regular dialysis. In actual fact, the responses given are very often a reflection of the legislation in force in the country rather than of its ethics' [my emphasis] (2).

The second document tabulates the effect of current legislation in member states of the Council of Europe (noting the lack of relevant legislation as appropriate, such as in the case of the United Kingdom) (3). The table concerned with genetically-related donors bears out the inconsistency and uncertainty to which the first document draws our attention (4).

Consequences and duties

Now it should not be surprising that the consequences 
of restrictions such as the 'genetic-relative' restriction make a difference to people's attitudes to those restrictions. Consequences are morally relevant. The whole reason that transplantation as an activity takes place at all is because we are interested in a certain kind of outcome - namely the saving of life, the recovery of the patient, and, most certainly, an improvement in his or her living conditions. There is nothing special about transplantation in this respect; the same could be said of health care as a whole. So, given that the 'geneticrelative' restriction clearly can have the consequence of limiting or perhaps denying the availability of a suitable donated organ, such a restriction demands the closest moral scrutiny.

But of course the morally relevant consequences of any policy can be many and varied. The passage quoted above comes from a larger section rather grandly entitled 'The possible effects of organ transplantation on man's future', and the context makes it clear that it is indeed for reasons of its consequences that the 'genetic-relative' restriction is being considered at all. But it is only later in the document that plausible adverse consequences of non-related donation emerge, in connection with 'trafficking' in organs, and the possible commercial exploitation of vulnerable living donors:

'West Germany's answer on this particular point (nongenetically related donors) is very clear: "Despite the prohibition on fees many people hold the view that the donation from living persons among non-relatives leaves the door open to perverting the intended purpose of transplantations. Even one case of abuse would be sufficient to jeopardise the treatment system of kidney transplantation." As well as being clear, this answer perhaps provides the outlines of a solution to this fundamental problem: $a$ ban on the removal of nonregenerative organs from a living human who is not closely and genetically related to the recipient [original emphasis] (5).

(The discussion then moves to possible exceptions to such a forthright policy, noting that 'The transplantation of organs between spouses need not be rejected out of hand. But this sensitive issue needs to be very carefully considered' (5).)

Clearly, then, outcomes are morally relevant to both sides of the case. Any attempt to argue either for, or against, the 'genetic-relative' restriction will certainly need to consider a plausible balance of good and harm. But considerations of duty and obligation also form part of our moral framework. We can have duties and obligations that appear to thwart the immediately or foreseeably beneficial consequences of our actions. It is perhaps largely in these terms that the European reservations concerning non-related donors are couched. We have, after all, a duty to protect the individual donor from the harm that might arise from his vulnerability to exploitation of any kind. It is harm of this kind that is envisaged in West Germany's warnings, quoted above. Even although the beneficial outcome of less cautious procurement policies is readily apparent - more organs are made available for the saving of life and the relief of suffering - it might be that this good could be bought only at the expense of a grave injustice to some individual donors.

Strikingly, our duties to safeguard the individual donor form the constant theme of the Council of Europe's discussion of ethical issues in transplantation. This focus becomes the more obvious when we contrast these European papers with discussions emanating from the United States, where the problems of procurement are dealt with in far more utilitarian style than are the problems of organ allocation, and where questions of duty and obligation emerge primarily with regard to the recipient rather than to the donor (6). And this reminds us that, like the arguments over consequences, the arguments over duties and obligations are also many-sided. Such arguments can incline us in either direction. Therefore in making a case either for or against the use of nonrelated living donors, we must take into account all our relevant duties.

I wish to argue that we should not enforce any restriction limiting live organ donation to genetic relatives. In many cases, clinical considerations and the happier facts of family life will dictate our choice of donor. But in the other cases we will be faced by the continuing need for suitable organs. Cadaver organs will meet a portion of this need. But some need will remain unmet. So I propose to counter the two principal objections to non-related donation, and to consider three further arguments in support of such donation. My aim is to show that in meeting the objections, we will be able positively to justify nonrelated donations as a way of meeting some of the remaining need for organs.

The two principal objections, as we have seen, concern the vulnerability of non-related donors to exploitation, and the vulnerability of the whole practice of transplantation to commercialism and 'trafficking'. Let us consider these first.

\section{The exploitation of the vulnerable}

This objection takes as its starting point the assumption that the range of potential live organ donors includes those who are vulnerable to undue or harmful pressure to donate. Thus, if they face such pressure and succumb to it, their reasons for donating will be doubtful both morally and practically. Not only will they fail to attain that altruism which is the hallmark of the 'ideal' donor, but they may be putting themselves at serious risk. No act of organ donation is entirely free from clinical risk, and it is therefore essential that donation be entirely free, informed and voluntary. None of these characteristics can properly attend any donation which is the result of undue pressure.

So far, so good. However, as an argument against nonrelated donation, this objection makes a second, and 
highly questionable assumption - namely that it is nonrelated donors who are specially, even uniquely, at risk in this way. Yet the moment that we consider the psychological and emotional pressure that must necessarily befall the living relatives of any needy recipient, we can see that this assumption falls. The tally of those who are most vulnerable to exploitation certainly includes those who are most vulnerable to undue pressure. And the psychological and emotional pressure upon the near relatives of the intended recipient is clearly very great. No doubt this pressure is importantly different from, say, the pressure of financial inducement. But it is nonetheless pressure, and it is hardly less likely to lead to exploitation of those vulnerable to it. Furthermore, this pressure is actually intensified by any formal restriction which rules out donations from non-relatives. Thus the objection from vulnerability fails.

\section{The risk of trafficking}

This is a development of the objection from vulnerability, foreseeing the very worst consequences of the possibility of exploitation, namely that such a possibility will be seized upon by those who wish to make a commercial profit. The objection assumes, perhaps, that financial pressure is furthermore the most irresistible kind. No doubt in certain circumstances it is, although this assumption would be hard to sustain in the general cases where a genetic relative is successfully matched to a needy recipient, but remains in doubt as to whether he or she really wishes to undergo the procurement surgery.

More importantly, if put forward as an acknowledgement of this objection, a formal 'geneticrelative' restriction would be misplaced. The way to prevent trafficking is to act against those who would actually take commercial advantage of the need for organs, that is, those who would undertake the procurement arrangements on a solely commercial basis. In the United Kingdom we already have a precedent for such action. The legislation following the Warnock Committee's report did not ban all surrogacy arrangements, but only commercial surrogacy arrangements, simply identifying any commercial actors themselves, rather than the medical staff or the commissioning parents, as the proper targets for prosecution. This seems entirely the right model for organ procurement.

The moral evil in trafficking stems, not from the donation of organs by a non-relative, but from the profit-directed commercial arrangements which would certainly lead to exploitation of the financially vulnerable. Thus the proper response is to attack the exploitation of the act of donation, not the act itself. It seems entirely appropriate to use a licensing authority similar to that envisaged by Warnock, as a means of dealing with the problem of organ trafficking. Such machinery leaves the acceptable source of donor organs an open question. As such, it properly identifies the outcomes to be avoided, and specifically deals with them.
There are three further arguments that may be put in favour of non-related organ donation.

\section{Availability of donor organs}

This is the simple consequentialist argument that the less restricted the pool of potential live donors, the greater the possibility of achieving a suitable match in any given case of need. There is already a scarcity of available organs for transplantation. This scarcity is made unnecessarily worse by any unnecessary restriction - a point that should not be neglected merely because it seems obvious.

For those who prefer to base their moral claims on duties rather than on outcomes, we need only reemphasise that our duty to safeguard individual donors from harm accompanies a further duty, the duty to maximise the recipient's chances of receiving lifesaving treatment.

\section{Altruism}

The case for transplantation as an activity relies heavily on the altruistic nature of any truly voluntary donation. For instance, in the summary of the case against nonrelated donors, from which I have quoted above, we find the claim that 'Everyone will agree that organ donation is one of the finest gestures of fraternity and love of which man is capable' (7).

Any 'genetic-relative' restriction clearly debars virtually the whole of humanity from the opportunity of such fraternity and love in any given case of need for an organ. It seems therefore perverse to emphasise this altruism and then grossly to circumscribe its opportunities for expression.

The discussion I have referred to does envisage the possibility that a legal relative - a spouse - may be exempt from the restriction. This is an important admission, because it brings with it the recognition that altruism may be mediated by significant and powerful emotions, which are not plausibly confined to genetic- or even legal-relatives. If emotion is to be a significant factor, then it would be bizarre to prevent a patient from receiving an organ donated by a willing friend.

Moreover it might be thought that altruism receives its highest expression in the absence of personal relationships - that is, when there can be no question of even emotional self-interest. The gift of an organ to a complete stranger, whose identity is concealed from the donor and from whom the donor's identity is concealed, seems worthy of the highest respect. Any formal restriction to related donors would rule out altruism of this supreme kind.

\section{Consistency with blood and bone-marrow donation}

An examination of the predominant European policies in these areas makes it clear that the clinical criteria for donor selection, namely HLA compatibility, suggest but do not dictate looking for sources from among genetic relatives $(8)$. The various ethical considerations concerning absence of gratuities, anonymity, fullyinformed consent and so forth, are expressly directed 
at non-relatives.

The difference between donating bone marrow and donating a kidney is that bone marrow is regenerative whereas kidneys are not. But kidneys are double organs, and the donor is not directly threatened by the loss of one of them. It is hard to reconcile the contrary approaches to the acceptability of non-relatives found in the respective policies on bone-marrow and kidney donation. The distinction can only hang on the regenerative nature of the one and not of the other. This distinction cannot support a claim that one is more vulnerable to exploitation or to trafficking than the other, nor that the one act of donation represents a lower ideal, a lower form of altruism than the other.

So, although consistency is only a provisional reason for adopting a particular policy, the striking absence of a 'genetic-relative' restriction in the area of blood- and bone-marrow transplantation undermines the case for such a restriction in the field of whole-organ donation. A moral distinction sufficient to introduce the restriction here could not depend on the objections actually put forward, and considered and dismissed above.

\section{In conclusion}

Transplantation as an activity is carried out - and is morally defended - for reasons of beneficial outcome. Policies which safeguard the interests of potential donors should therefore be seen as a proper and cautionary exercise of duties, in what is essentially a context of outcomes. Whilst it is obviously right that we should safeguard the interests of potential donors, it is also right that we should do so in a way which does not unnecessarily inhibit the availability of already scarce donor organs.

The principal arguments for a 'genetic-relative' restriction have been shown to fail, and I have argued that, in terms of our duty to maximise the possibilities of successful treatment for the patient, we should indeed be prepared to accept whole organs from clinically suitable and genuinely willing donors who are neither genetically nor legally related to the intended recipient.

Martyn Evans BA PhD is University College Fellow at the Centre for Philosophy and Health Care, University College of Swansea, Singleton Park, Swansea SA2 8PP.

\section{References}

(1) Conference of European Health Ministers, Paris, 16-17 November 1987.

(2) Council of Europe. Organ transplantation, first report: ethical and socio-cultural problems raised by organ transplantation Strasbourg: Council of Europe, 1987: 9 [my emphasis].

(3) Council of Europe. Organ transplantation: current legislation in Council of Europe member states and Finland, and results of European co-operation Strasbourg: Council of Europe, 1987.

(4) See reference (3): 19-20.

(5) See reference (2): 16 [original emphasis].

(6) For instance, see Transplantation proceedings, XX; 1 suppl 11988 Feb: 1011-1032.

(7) See reference (2): 9.

(8) Council of Europe. Organ transplantation: the establishment of a European registry of HLA-typed volunteer donors. Strasbourg: Council of Europe, 1987. 